\title{
Research on the Comprehensive Evaluation of the Higher Education System Based on FCE and ARMA Models
}

\author{
Xin-Hong Xu $\mathbb{D}^{\mathbb{D}},{ }^{1,2}$ Lei Ye $\mathbb{D}^{3},{ }^{3}$ Yu Pei $\mathbb{D}^{4},{ }^{4}$ Lin Zhao $\mathbb{D}^{4},{ }^{4}$ and Jing-Jing Wang $\mathbb{D}^{5}$ \\ ${ }^{1}$ School of International Education, Shandong University, Jinan, Shandong 250100, China \\ ${ }^{2}$ Art College, Anhui University of Finance and Economics, Bengbu 233030, China \\ ${ }^{3}$ School of Economics, Anhui University of Finance and Economics, Bengbu 233030, China \\ ${ }^{4}$ School of Statistics and Applied Mathematics, Anhui University of Finance and Economics, Bengbu 233030, China \\ ${ }^{5}$ School of Languages and Media, Anhui University of Finance and Economics, Bengbu 233041, China \\ Correspondence should be addressed to Jing-Jing Wang; wangjingjing0301@126.com
}

Received 20 August 2021; Revised 8 December 2021; Accepted 22 December 2021; Published 24 February 2022

Academic Editor: Sheng Du

Copyright $\odot 2022$ Xin-Hong Xu et al. This is an open access article distributed under the Creative Commons Attribution License, which permits unrestricted use, distribution, and reproduction in any medium, provided the original work is properly cited.

\begin{abstract}
A Higher education system is closely related to a country's development. Governments need to make appropriate adjustments to ensure the healthy and sustainable development of higher education. To measure and evaluate the development status of the national higher education system and propose a set of policies, the following work has been done in this paper: First, this paper establishes a comprehensive evaluation index system based on the AHP-FCE model. The healthy development of education in significant countries was compared horizontally and vertically. The results of weighted scores were used to determine the Japanese higher education system as the research object. Secondly, this paper uses factor analysis and principal component analysis to evaluate the level of sustainable development of higher education, detecting development barriers that migrate from the current to the future. This paper proposes a healthy and sustainable development policy blueprint from four aspects. Finally, this article uses the ARMA time series model to predict the development trend of Japanese higher education in the next 30 years and formulates a timetable for corresponding implementation arrangements. In addition, this paper quantitatively evaluates the effectiveness of the policies we propose and their impact on reality and provides references for other countries in the world.
\end{abstract}

\section{Introduction}

The higher education system refers to the organizational structure of higher education institutions and the personnel and infrastructure required to educate students beyond the secondary level. For a country, having a healthy and sustainable higher education system can train more comprehensive talents, etc. In the world, there are many ways of higher education in various countries. Each country not only teaches students but also attracts a large number of international students every year.

Each country's higher education system has its strengths and weaknesses. Under the current pandemic situation, each country will make necessary adjustments to its domestic higher education system. After this adjustment, the advantages and disadvantages of the higher education system will gradually emerge. We try to develop a model to measure and evaluate the health level of the higher education system at the national level. To determine a healthy and sustainable state for the higher education system of a given country, this article proposes and analyzes a set of policies to push the development of Chinese higher education to a new stage.

Based on the current level of development of higher education, this article discusses the following aspects: (i) Establish an input-output indicator system and use relevant data to assess the health status of the higher education system in various countries. (ii) According to the results of the model, aspects of higher education that need improving are analyzed. (iii) A reasonable future vision for the selected country is proposed. (iv) The health and sustainable development of higher education in the country is measured. (v) A reasonable estimate of how to achieve the ideal state 
and a specific policy and its implementation timetable is proposed. (vi) The effectiveness of our proposed policies is quantitatively evaluated. (vii) The impact of policy plans on reality is analyzed.

The general idea of this article is shown in Figure 1.

\section{Literature Review}

Higher education evaluation activities have a long history. Still, as an important educational system arrangement, they emerged in major countries such as Europe and the United States at the beginning of the twentieth century. They produced the rapid development of modern higher education [1]. Although there are only more than a hundred years, the evaluation activities of higher education are extremely active [2]. The high-quality development of higher education is better to meet the people's demand for high-quality higher education. The core of its development is to improve quality as the fundamental goal, with fairness and diversification as the main goal. The starting point and ultimate goal of the high-quality development of higher education must always be positioned and answered in the basic propositions of "who to train, how to train, and for whom" [3]. Regarding what is the high-quality development of higher education, existing research mainly analyzes it from the following three perspectives.

From the perspective of evaluation methods, research mainly focuses on feedback, formative evaluation, and peer evaluation [4]. In the era of big data, it is necessary to be good at using data and evaluation methods. As a powerful mechanism, data can help teachers, higher education administrators, and students form a scientific feedback mechanism for regular evaluation of evaluation, enabling evaluation research, and paying attention to a wider range of people. Extensive data-driven evaluation methods can ensure the independence of evaluation and reduce the randomness of assessment. Yang et al. constructed a two-stage network model and used Luenberger indicators to analyze Chinese research universities' productivity and evolution process [5]. Bond et al. looked at the status quo of higher education evaluation from a practical perspective based on the experimental evaluation. They propositioned as a part of higher education curriculum practice, ending the separation of evaluation and teaching and learning [6]. The use in higher education evaluation can be used to judge the authenticity and rationality of the evaluation. The reliability and validity of the evaluation can ultimately determine whether the research results are meaningful. In the evaluation of higher education, the reliability and validity of the evaluation model are often tested [7]. For example, Hasan and Hamzeh explore students' views from regions outside the west on the curriculum, using the structural validity test to prove the rationality of the questionnaire model [8]. Green researched articles using structural equation modeling (SEM) in international higher education research. SEM can also test alternative models, reliability and validity, theoretical support models, and data screening in higher education research. Fitting index and other aspects are improved to provide the best practice statistical guidelines for higher education evaluation research [9].

From the perspective of evaluation indicators, the research focuses on student-centered and timeliness of evaluation. Higher education evaluation must ensure quality while achieving substantial breakthroughs and building an evaluation system with clear evaluation goals. In modern society, critical thinking is generally regarded as one of higher education goals [10]. Tannock uses advanced evaluation as an example to demonstrate the importance of public universities in cultivating students' critical, reflective, independent, and democratic thinking. The author believes that public universities should use the "graded evaluation" evaluation method to carry out scientific reforms to ensure the rationality of the higher education system [11]. The Higher Education Learning Outcome Evaluation (AHELO) faces challenges such as the validity of scores and score interpretation and learned from AHELO feasibility studies and other international evaluation studies to provide references for future international higher education evaluations [12].

From the perspective of evaluation quality, research focuses on the reliability and validity of an evaluation. In the era of big data, we must be good at using data to analyze the relevance of evaluation indicators, the applicability of evaluation methods, and the representativeness of evaluation subjects to grasp evaluation quality. Through dynamic data analysis, real-time monitoring of the evaluation and necessary early warning can be carried out, dynamic evaluation can be constructed, and timely feedback can be provided to improve the evaluation. Harper et al. investigated the problem of "contract cheating" in evaluating Australian higher education by students outsourcing the evaluation to a third party. The research results show that "contract cheating" can be solved by improving the teaching environment, such as improving the teacher-student relationship [13]. Bearman et al. address the issue of "transparency" in higher education evaluation standards and propose that teachers can design evaluation materials, such as rulers, task descriptions, and examples to convey their intentions. At the same time, they also encourage students to develop their work and learning methods [14].

\section{Assumptions and Symbols}

In response to the problems studied in this article, to better establish the model without affecting the accuracy of the model, we have made the following assumptions: (i) it is assumed that the indicators selected in this article can well represent the comprehensive level of higher education development in the country; (ii) it is assumed that the indicators selected in this article can be effectively predicted; (iii) it is assumed that the trend of the comprehensive level of higher education development in all the sample countries selected in this article in the next ten years will be the same as the previous 20 years and will not be changed due to systematic adjustments. (iv) it is assumed that this article's policy recommendations and plans can be implemented without interference from external factors. At the same time, the abbreviations and definitions mentioned in this article are shown in Table 1. 


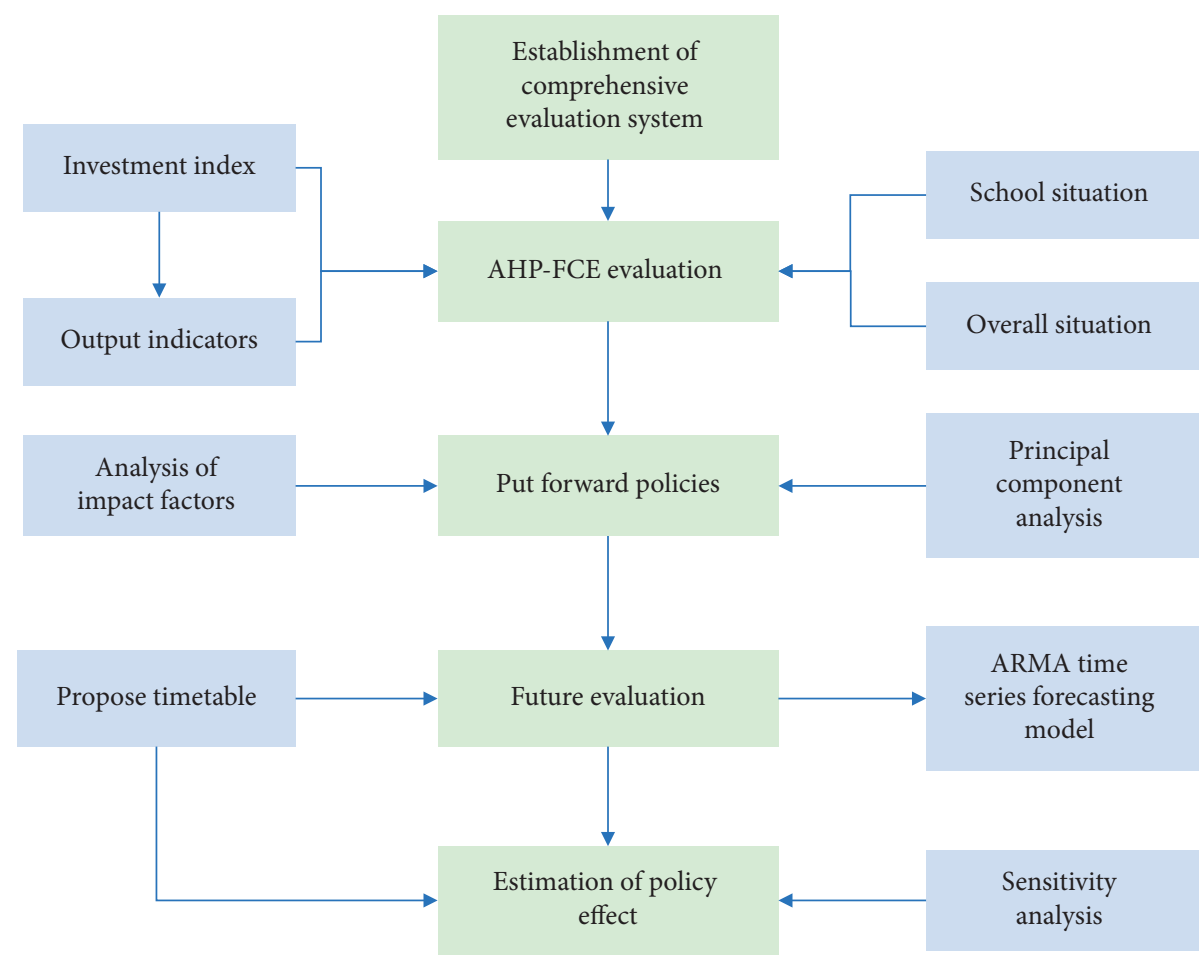

FIgURE 1: Overall thinking process.

TABle 1: Symbols.

\begin{tabular}{lccc}
\hline Symbols & Definition & Symbols & Definition \\
\hline AHP-FCE & Fuzzy hierarchical integrated evaluation method & ARMA & Autoregressive moving average model \\
AHP & Analytic hierarchy process & FCE & Fuzzy comprehensive evaluation model \\
ADF & Augmented dickey-fuller test & FV & Future values \\
LCL & Lower control line & $\mathrm{UCL}$ & Upper control line \\
$\mathrm{KMO}$ & Measure of sampling adequacy & $A_{\mathrm{ij}}$ & Judgement matrix \\
$W_{i}$ & Eigenvectors & $\lambda_{\max }$ & Maximum eigenvalue \\
$\mathrm{CI}$ & Consistency indicator & $\mathrm{RI}$ & Random consistency indicator \\
$\mathrm{CR}$ & Consistency ratio & $W_{\mathrm{ij}}$ & Weights of index $i j$ \\
$X_{i}$ & p-dimensional random vector of index $i$ & $\mu_{i}$ & Index is the mean value of $i$ \\
$F_{i}$ & q-dimensional random vector of index $i$ & $\varepsilon_{i}$ & Special factor with index $i$ \\
$Y_{t}$ & Observed values & $e_{t}$ & Errors \\
$H_{i}$ & Undetermined factors & $\theta_{j}$ & Uncertainty factor of the model \\
\hline
\end{tabular}

\section{Comprehensive Evaluation of Higher Education Development}

4.1. Establish an Evaluation Index System. The first step in constructing an evaluation index system is to select evaluation indexes. The choice of indexes largely determines the pros and cons of the model. The comprehensive level of a country or region's higher education development system itself, its future development potential, and the social value behind it can be studied separately. Based on the previous literature and theoretical analysis, referring to the existing data research and the availability of data, this article constructs an evaluation system of the health status of the higher education system from the four dimensions of the school situation, input, output, and overall situation. When selecting specific indicators, this article also considers whether the indicators are comparable and relevant, whether they can be applied on a large scale in the world, and so on. In the end, 15 indicators are selected to construct the evaluation index system, a complete evaluation index for the development of higher education. The system is shown in Table 2. Data for all indicators come from the World Bank database and Knoema.

4.2. Introduction to the AHP and Fuzzy Comprehensive Evaluation Method. The Analytic Hierarchy Process, abbreviated as AHP, is a level weight decision analysis method proposed by T. L. Saaty. The principle of the analytic hierarchy process is to decompose the problem into different 
TABLE 2: Comprehensive evaluation index system of higher education.

\begin{tabular}{|c|c|c|c|}
\hline Target layer & First-level index layer & Second-level index layer & Marks \\
\hline \multirow{15}{*}{ Development of higher education } & \multirow{5}{*}{ School situation } & Per capita expenditure of college students/GDP & $A_{1}$ \\
\hline & & Higher education gross enrollment rate & $A_{2}$ \\
\hline & & Teacher-student ratio & $A_{3}$ \\
\hline & & The proportion of international students & $A_{4}$ \\
\hline & & The proportion of college students & $A_{5}$ \\
\hline & \multirow{4}{*}{ Investment index } & Education as a share of GDP & $B_{1}$ \\
\hline & & Public education as a proportion of total expenditure & $B_{2}$ \\
\hline & & Education as a share of GNI & $B_{3}$ \\
\hline & & $R \& D$ expenditure as a percentage of GDP & $B_{4}$ \\
\hline & \multirow{3}{*}{ Output indicators } & Employment rate & $C_{1}$ \\
\hline & & Per capita scientific journal articles & $\mathrm{C}_{2}$ \\
\hline & & Patent applications per capita & $C_{3}$ \\
\hline & \multirow{3}{*}{ Overall situation } & Knowledge-economy index & $D_{1}$ \\
\hline & & Number of R\&D researchers & $D_{2}$ \\
\hline & & High-tech exports as a proportion of manufacturing exports & $D_{3}$ \\
\hline
\end{tabular}

components according to the nature of the problem and the overall goal to be achieved, and according to the interrelationship between the factors and the affiliation relationship. The factors are gathered and combined at different levels to form a multilevel analyze the structural model and finally make the problem boil down to the determination of the relatively significant weight of the lowest level relative to the highest level or the arrangement of the relative order of superiority and inferiority [15]. The analytic hierarchy process is more suitable for decision-making problems with hierarchical and interlaced evaluation indicators, and the target value is difficult to describe quantitatively. Therefore, we choose AHP as the primary evaluation method for the comprehensive level of higher education development.

The fuzzy comprehensive evaluation method is a comprehensive evaluation method based on fuzzy mathematics [16-20]. This comprehensive evaluation method transforms qualitative evaluation into quantitative evaluation based on the membership degree theory of fuzzy mathematics, that is, using fuzzy mathematics to make an overall evaluation of things or objects restricted by multiple factors. It has the characteristics of precise results and strong systematicity. It can also better solve vague and difficult quantity problems. And it is suitable for solving various nondeterministic problems. Among the selected indicators, the four indicators, namely the number of scientific journals published per capita, the number of patent applications per capita, the knowledge economy index, and the number of R\&D researchers, are all numerical data. The results will be unstable if the numerical data is directly substituted into the model calculation [21]. This will result in the distortion of the calculated score for the comprehensive development level of higher education. To avoid this result, this paper chooses the concept of fuzzy set in the fuzzy comprehensive evaluation method, first processes the data of these four indicators, and then substitute it into the model to calculate the score.

4.3. Data Standardization. Borrowing the concept of fuzzy sets to process the four indicators' data, it is necessary to set the membership function to calculate the degree of membership in the fuzzy set theory. This article also uses this idea to convert the original data of the indicator into an interval value of $(0-1)$ through the membership function, making it like ratio data. This is done to increase the comparability of the indicator and make the final model more reasonable.

The membership function of the number of scientific journals published per capita is $A_{\left(C_{2}\right)}$ :

$$
A_{\left(C_{2}\right)}=\left\{\begin{array}{l}
0.1, C_{2} \leq 0.5 \\
0.2,0.5<C_{2} \leq 3 \\
0.4,3<C_{2} \leq 8 \\
0.6,8<C_{2} \leq 15 \\
0.8,15<C_{2} \leq 20 \\
0.9, C_{2}>20
\end{array}\right.
$$

The membership function of the number of patent applications per capita is $A_{\left(C_{3}\right)}$ :

$$
A_{\left(C_{3}\right)}=\left\{\begin{array}{l}
0.1, C_{3} \leq 1 \\
0.2,1<C_{3} \leq 3, \\
0.4,3<C_{3} \leq 5, \\
0.6,5<C_{3} \leq 8, \\
0.8,8<C_{3} \leq 10, \\
0.9, C_{3}>10 .
\end{array}\right.
$$

The membership function of the knowledge economy index is $A_{\left(D_{1}\right)}$

$$
A_{\left(D_{1}\right)}=\left\{\begin{array}{l}
0.2, D_{1} \leq 2.5 \\
\frac{D_{1}-2.5}{(8-2.5)}, 2.5<C_{3} \leq 8 \\
0.9, D_{1}>8 .
\end{array}\right.
$$

The membership function of the number of $\mathrm{R} \& \mathrm{D}$ researchers is $A_{\left(D_{2}\right)}$ 


$$
A_{\left(D_{2}\right)}=\left\{\begin{array}{l}
0.2, D_{2} \leq 5, \\
0.3,5<D_{2} \leq 10, \\
0.4,10<D_{2} \leq 20, \\
0.5,20<D_{2} \leq 40, \\
0.7,40<D_{2} \leq 60, \\
0.9, D_{2}>60 .
\end{array}\right.
$$

According to the above method, a standard data set can be obtained.

4.4. Calculate Results. By combining related materials with the actual situation of life, the relationship and importance of various indicators in higher education's comprehensive development evaluation system are analyzed, establishing a pairwise comparison matrix [22, 23].

The elements in each column of the judgment matrix are standardized. The general terms of the elements are as follows:

$$
A_{\mathrm{ij}}=A_{\mathrm{ij}} \div \sum_{i, j=1}^{n} A_{\mathrm{ij}} .
$$

After normalization, use the sum and product method to calculate and add the judgment matrix of each column. $W_{i}$ has been obtained.

$$
W_{i}=\sum_{i, j=1}^{n} B_{\mathrm{ij}} .
$$

The element $W_{i}$ is a ranking weight value of the relative importance of a factor of the same level to a factor of a higher level.

$$
W=\left(W_{1}, W_{2}, \ldots, W_{n}\right)^{T} .
$$

In the normalization process, the approximate solution of the feature vector is obtained. Calculate the maximum eigenvalue of the judgment matrix $\lambda_{\max }$

$$
\lambda_{\max }=\sum_{i=1}^{n} \frac{(\mathrm{AW})_{i}}{\mathrm{nW}_{i}} .
$$

After that, we can ensure that the ranking is consistent with the consistency check. The so-called consistency check is the allowable range of $\mathrm{A}$. is

The consistency index of the pairwise comparison matrix

$$
\mathrm{CI}=\frac{\lambda_{\max }-n}{n-1} .
$$

To measure the size of CI, a random consistency index RI is introduced. The method is as follows: randomly construct 500 pairwise comparison matrices and obtain the consistency index.

$$
\mathrm{RI}=\frac{\mathrm{CI}_{1}+\mathrm{CI}_{2}+\cdots+\mathrm{CI}_{500}}{500} .
$$

The ratio of the consistency index CI. The random consistency index RI expressed in the same order is called the random consistency ratio (CR).

$$
\mathrm{CR}=\frac{\mathrm{CI}}{\mathrm{RI}} \text {. }
$$

The $\mathrm{CR}<0.1$ was obtained through the level analysis software and passed the consistency check. The feature vector is calculated by formula (7), that is, the weight of each index. The index weights are shown in Table 3.

After obtaining the index weights, a comprehensive evaluation model of the development level of higher education can be established, $w_{\mathrm{Aj}}, w_{\mathrm{Bj}}, w_{\mathrm{Cj}}, w_{\mathrm{Dj}}$ are the weight of each indicator; $A_{j}, B_{j}, C_{j}, D_{j}$ are the data value of each indicator [24].

$$
\begin{aligned}
& S_{A}=\sum_{j=1}^{5} w_{\mathrm{Aj}} A_{j}, \\
& S_{B}=\sum_{j=1}^{4} w_{\mathrm{Bj}} B_{j}, \\
& S_{C}=\sum_{j=1}^{3} w_{\mathrm{Cj}} C_{j}, \\
& S_{D}=\sum_{j=1}^{3} w_{D j} D_{j}, \\
& S=S_{A}+S_{B}+S_{C}+S_{D} .
\end{aligned}
$$

Substituting the index data sets of the selected 18 countries in the first 20 years into the model (16), after calculation, the evaluation scores of the comprehensive development level of higher education in each country in the 20 years from 2001 to 2020 are obtained. The results are shown in Figures 2 and 3.

\section{Putting Forward Improvement Policy}

5.1. Principal Component Analysis. For selected countries, this article uses SPSS software principal component analysis to model and analyze higher education data in countries and regions that need to be improved. In addition, this paper performs dimensionality reduction processing on 15 indicator variables, eliminating the less influential indicators and reducing the application of such indicators; on this basis, the indicators with more significant impact have been determined, further expanding their scope of influence and making breakthroughs in the education system [25]. The data analysis results are shown in Table 4.

The results of the principal component analysis calculated by the software are as follows: According to the principle that the characteristic value is greater than 1 , the principal component analysis method is used to extract a total of 4 principal factors, and the cumulative variance contribution rate is $86.967 \%$, which represents most of the information $[26,27]$. These four main factors can replace all 
TABLE 3: The weight of each indicator.

\begin{tabular}{lcccccccc}
\hline Index & $\mathrm{A} 1$ & $\mathrm{~A} 2$ & $\mathrm{~A} 3$ & $\mathrm{~A} 4$ & $\mathrm{~A} 5$ & $\mathrm{~B} 1$ & $\mathrm{~B} 2$ & $\mathrm{~B} 3$ \\
\hline Weights & 0.0453 & 0.0842 & 0.0615 & 0.0374 & 0.0215 & 0.0521 & 0.0389 & 0.0302 \\
Index & $\mathrm{B} 4$ & $\mathrm{C} 1$ & $\mathrm{C} 2$ & $\mathrm{C} 3$ & $\mathrm{D} 1$ & $\mathrm{D} 2$ & $\mathrm{D} 3$ & - \\
Weights & 0.0289 & 0.0809 & 0.0867 & 0.0825 & 0.1364 & 0.1399 & 0.0738 & - \\
\hline
\end{tabular}

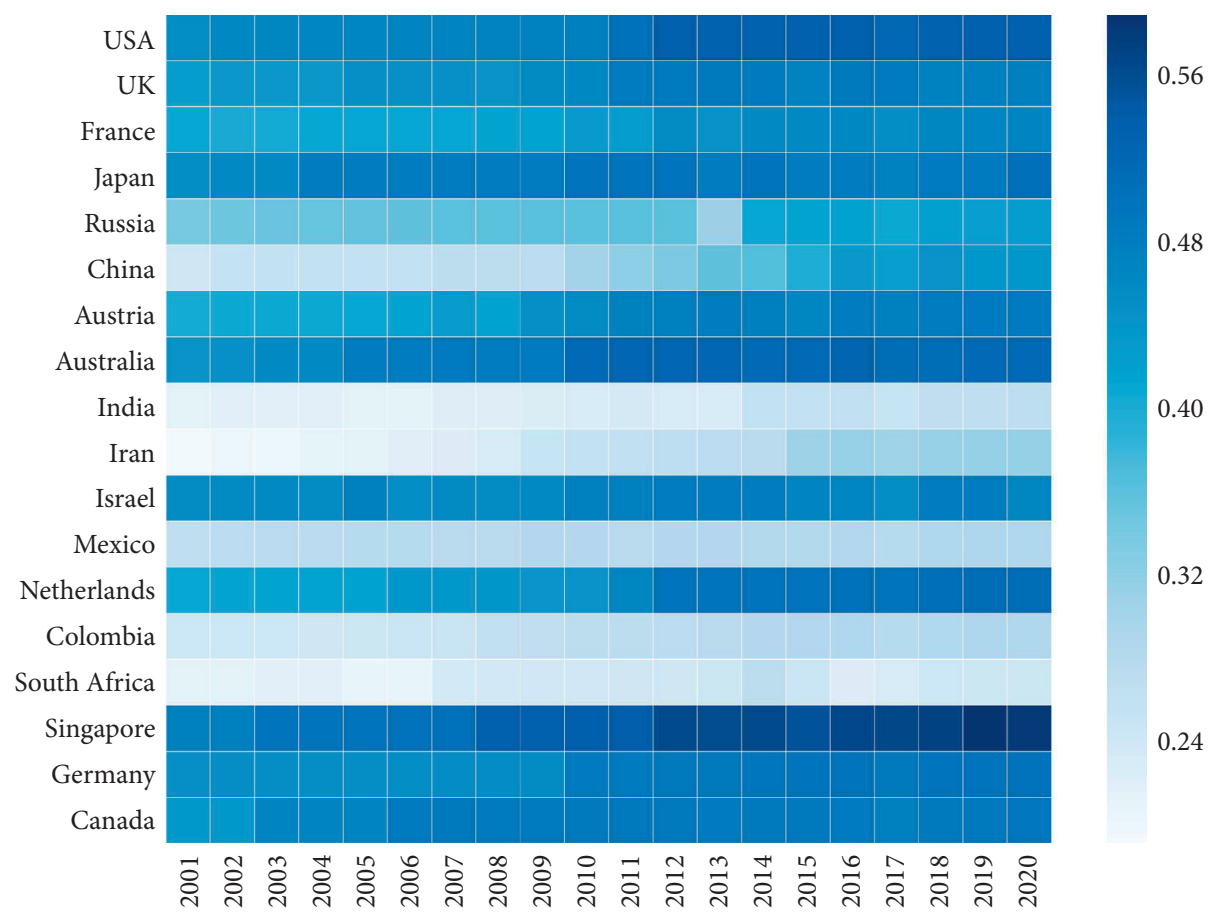

FIgURE 2: The scores of higher education development in various countries in the past 20 years.

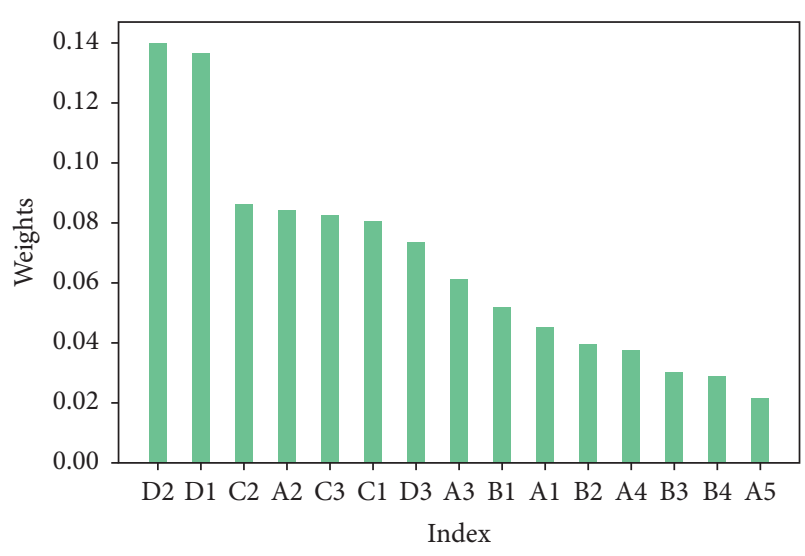

Figure 3: The weight of each indicator.

the original indicators to describe the development of higher education in Japan. The eigenvalues and variance contribution rates corresponding to the 4 main factors are shown in Table 4 . It can be seen that the variance contribution rate of the first main factor is the largest (33.997\%), which is the most important influence factor; the variance contribution rate of the second leading factor. Secondly, it is the second most important influencing factor; the variance contribution rate of the third and fourth main factors is lower than that of the first two.

The first influencing factor is the gross enrollment rate of higher education, which belongs to the school level. The gross enrollment rate of colleges and universities is an important factor that affects the scale of colleges and universities. The second influencing factor is the ratio of public education expenditure to total expenditure, the investment level. The financial investment can significantly affect the quality of colleges and universities' investment in running schools and has a decisive effect. The third influencing factor is the teacher-student ratio, which belongs to the school level. The teacher-student ratio can reflect the efficiency of the utilization of human resources in colleges and universities. The fourth impact factor is the knowledge economy index, which belongs to the overall national level. Therefore, it can be concluded that the indicators that lead to the imperfection of the Japanese higher education system are mainly caused by school and social investment. [28].

5.2. A Blueprint for the Higher Education System. As one of the world's higher education powers, Japanese higher education has been popularized. By the beginning of this century, Japan had established a complex and 
TABle 4: Principal component extraction analysis of total variance explanation.

\begin{tabular}{lcccccccc}
\hline & \multicolumn{3}{c}{ In. } & \multicolumn{3}{c}{ Initial eigenvalue } & \multicolumn{3}{c}{ Extract the sum of squares of the } & \multicolumn{2}{c}{ Rotating load sum of squares } \\
& Total & Var. & Gra. & Total & Var. & Gra. & Total & Var. \\
\hline 1 & 5.10 & 33.99 & 33.99 & 5.10 & 33.99 & 33.99 & 4.75 & 31.69 \\
2 & 2.99 & 19.94 & 53.93 & 2.99 & 19.93 & 53.93 & 2.82 & 18.82 \\
3 & 2.53 & 16.89 & 70.83 & 2.53 & 16.89 & 70.82 & 2.11 & 14.07 \\
4 & 1.67 & 11.16 & 81.99 & 1.67 & 11.16 & 81.98 & 1.93 & 12.90 \\
5 & 0.75 & 4.98 & 86.97 & 0.75 & 4.98 & 86.96 & 1.42 & 9.47 \\
6 & 0.56 & 3.71 & 90.68 & - & - & - & - & - \\
7 & 0.43 & 2.88 & 93.56 & - & - & - & - & - \\
8 & 0.36 & 2.41 & 95.97 & - & - & - & - & - \\
9 & 0.21 & 1.39 & 97.35 & - & - & - & - & - \\
10 & 0.20 & 1.34 & 98.69 & - & - & - & - \\
11 & 0.13 & 0.87 & 99.56 & - & - & - & - \\
12 & 0.04 & 0.24 & 99.79 & - & - & - & - \\
13 & 0.03 & 0.17 & 99.97 & - & - & - & - \\
14 & 0.02 & 0.03 & 100.00 & - & - & - & - \\
15 & 0.01 & 0.01 & 100.00 & - & - & - & - \\
\hline
\end{tabular}

comprehensive quality assurance system with various forms and multiple subjects, including government evaluation, university self-evaluation, and third-party evaluation. However, since the 1990s, in education, the Japanese government has formulated and implemented a series of policies aimed at slowing down compliance and promoting the autonomy of higher education institutions. The development of the Japanese higher education system is in contradiction with its quality evaluation and guarantee system, and to a certain extent, has affected the goal of the globalization of the Japanese higher education system. [29, 30].

At present, the Japanese higher education system has certain deficiencies compared to other countries. We have established a hierarchical analysis model for higher education by carefully considering various factors and selecting four main components using principal component analysis. It is found that the shortcomings of Japanese higher education are more prominent in three aspects: school, community, and country.

\subsubsection{In terms of School}

(1) The problem. There is a contradiction between the hierarchical evaluation system and the autonomy and self-discipline development of universities.

(2) Solution. Under this circumstance, we believe that universities can establish a quality evaluation system that is compatible with university development. At the same time, universities need to strengthen the link between evaluation results and financial allocations and increase the openness and transparency of evaluation results. To correctly and scientifically evaluate and improve the quality and service level of the school [31].

\subsubsection{In terms of Community}

(1) The problem. In the early 1990s, unfair admissions often occur due to family economy, parents' occupation, educational background.
(2) Solution. We believe it can be tried as an economic redistribution policy that eliminates the expansion of the higher education entrance gap and the intergenerational transmission chain of poverty and provides government financing subsidies for extracurricular tuition fees and examination fee loans for middle and high school graduating classes. The loaned funds will be fully exempted after the students formally obtain the qualifications for further studies. At the same time, a new scholarship policy for high school and college students can be formulated. The primary goal of these policies is to increase the college admission rate for children from families with financial difficulties. This will further expand the need for poor students to receive higher education, creating an educational environment for children from low-income families to study at ease. And ultimately, it can indirectly achieve fair access to higher education [32].

\subsubsection{In terms of Country}

(1) The problem. Japanese education expenditure as a percentage of GDP is at a relatively low level among OECD countries. Compared with other developed countries, the Japanese government invests less in higher education.

(2) Solution. We believe that the Japanese government can increase its investment in national school education, which can provide education subsidies for students whose families are in financial difficulties $[33,34]$.

5.2.4. Summary of Expectations. From the perspective of goal orientation, the school-running philosophy should be based on the people's needs for higher education and social investment. The country should pursue fair and diversified goal orientation. From educational development, the school 
level should put the characteristics of diversified development of higher education in a prominent position. At the same time, society and the country should focus on improving the ability to serve economic and social development. From the perspective of education quality, the school level should firmly grasp the quality and realize the transformation of higher education development to a high-quality development mode. Social investment and the country should correctly guide the quality concept of colleges and universities to achieve all-around development. If the above points can be earned, the Japanese higher education system will be more complete, and the gap with other developed countries will become smaller and smaller.

\subsection{Variable Classification Based on Factor Analysis.} Considering the need to study the internal dependence and basic structure between different indicators, we intend to use factor analysis to measure the health of the country's current and healthy sustainable systems [35]. The basic idea of factor analysis is to classify the observed variables and group closely related ones into the same category. The essence of factor analysis is to establish a linear mapping from a highdimensional space to a low-dimensional space. The mapping maintains some structure of the sample points in the highdimensional space. And it converts multiple indicators into a few comprehensive indicators with the idea of dimensionality reduction. These few unmeasured comprehensive indicators are usually called common factors [34-36]. The mathematical model of factor analysis is generally expressed as follows:

$$
X_{\mathrm{i}}=\mu_{\mathrm{i}}+a_{i 1} F_{1}+\cdots+a_{\mathrm{iq}} F_{q}+\varepsilon_{i} .
$$

Among them, $X=\left(x_{1}, x_{2}, \ldots, x_{p}\right)^{T}$ is a $p$ dimensional random vector, the mean is $\mu$; $F=\left(f_{1}, f_{2}, \ldots, f_{q}\right)^{T}$ is a $q$ dimensional random vector $(q \leq p) ; \varepsilon_{i}$ is a noteworthy factor; $E(F)=0, E(\varepsilon)=0 \operatorname{Cov}(F, \varepsilon)=0 ; D(F)=I$.

Factor analysis generally requires three steps: judging the original variables, extracting main factors, and performing factor rotation. The specific process is as follows.

First, determine whether the original variable is suitable for factor analysis. According to the collected data and the classification of the comprehensive evaluation indicators in Table 4, a set of observation data is obtained for analysis. Because factor analysis requires a strong correlation between variables, the original variables must be correlated and tested before factor analysis. The SPSS statistical software is used to calculate the observation data, and the KMO test value is $0.742(>0.5)$. The significance efficiency of Bartlett's sphere test is $0.000(<0.05)$, indicating that the indicators have a strong correlation and are more suitable for factor analysis [37].

Secondly, extract the main factor. Then the specific results and analysis are obtained through principal component analysis.

Again, perform factor rotation. The degree of correlation between the main factor and the original variable index is characterized by the factor loading value. The larger the factor load value is, the more information the factor contains in the corresponding original variable index. To obtain a simpler structure and facilitate better interpretation of the factors, we use orthogonal rotation with maximum variance to rotate the factor loading matrix of the main factor. And after multiple rotations, the orthogonal rotation factor loading matrix of 4 main factors is obtained, according to Table 5.

5.3.1. The First Factor. The first common factor and the principal component load weight is $31.692 \%$, indicating the load value of the five indicators of per capita expenditure of college students, the gross enrollment rate of higher education, teacher-student ratio, and the proportion of international students.

5.3.2. The Second Factor. The load weight of the principal component of the second common factor is $18.829 \%$, indicating that the four indicators of education accounted for GDP ratio, public education accounted for total expenditure, education accounted for GNI, and R\&D expenditure accounted for GDP.

5.3.3. The Third Factor. The third common factor, the principal component loading weight, is $14.072 \%$, indicating that the employment rate, the number of scientific journal articles per capita, and the number of patent applications per capita have relatively large loading values, which are factors in terms of output.

5.3.4. The Fourth Factor. The fourth common factor has a principal component loading weight of $12.901 \%$, indicating that the three indicators of the knowledge economy index, the number of $R \& D$ researchers, and the proportion of hightech exports in manufacturing exports have relatively large loading values.

5.4. Comparison of the Status Quo and the Blueprint. In recent years, the Japanese government has attached great importance to the internationalization of higher education and vigorously promotes university reform and internationalization. Japan strives to strengthen higher education's versatility, enhance the international competitiveness of higher education, and ultimately improve training capabilities. The talents provide suitable environmental conditions. After Japan has made corresponding changes to its higher education system, school-age students have decreased year by year. The proportion of private schools has been significant [38]. Given the current gross enrollment rate of more than $50 \%$ and the characteristics of nonnational elite education, Japan has shifted the training model from elite education to mass vocational education in the education system, which has increased the popularity of higher education.

Compared with the existing system, and based on the existing cases in Japan, the existing system and the system 
TABLE 5: Rotation component matrix.

\begin{tabular}{|c|c|c|c|c|c|}
\hline \multirow{2}{*}{ Variable } & \multicolumn{5}{|c|}{ Main ingredient } \\
\hline & 1 & 2 & 3 & 4 & 5 \\
\hline 1 & 0.916 & 0.112 & -0.164 & -0.902 & -0.127 \\
\hline 2 & 0.827 & 0.278 & -0318 & -0.827 & -0.537 \\
\hline 3 & 0.818 & 0.056 & 0.383 & -0.891 & 0.818 \\
\hline 4 & 0.210 & 0.852 & -0.783 & -0.069 & 0.025 \\
\hline 5 & 0.795 & -0.219 & -0.807 & 0.037 & 0.015 \\
\hline 6 & 0.045 & 0.985 & -0.009 & 0.010 & -0.006 \\
\hline 7 & -0.042 & 0.925 & 0.008 & -0.007 & 0.003 \\
\hline 8 & 0.775 & 0.869 & 0.116 & 0.392 & -0.934 \\
\hline 9 & -0.274 & 0.760 & 0.194 & -0.524 & -0.826 \\
\hline 10 & -0.011 & 0.543 & -0.187 & -0.108 & -0.966 \\
\hline 11 & 0.012 & -0.115 & 0.998 & -0.850 & -0.065 \\
\hline 12 & -0.822 & 0.227 & 0.878 & -0.162 & 0.086 \\
\hline 13 & 0.841 & -0.094 & 0.427 & 0.077 & 0.090 \\
\hline 14 & -0.902 & -0.099 & 0.971 & 0.111 & 0.121 \\
\hline 15 & -0.910 & -0.034 & 0.854 & 0.154 & 0.013 \\
\hline 16 & 0.210 & -0.406 & 0.077 & 0.994 & -0.406 \\
\hline 17 & -0.822 & -0.108 & 0.121 & 0.910 & -0.108 \\
\hline 18 & -0.011 & -0.112 & 0.013 & 0.822 & -0.850 \\
\hline 19 & 0.383 & 0.090 & -0.406 & 0.902 & -0.187 \\
\hline 20 & -0.406 & 0.086 & -0.162 & -0.971 & 0.826 \\
\hline 21 & -0.112 & 0.013 & 0.086 & -0.406 & 0.822 \\
\hline 22 & -0.108 & -0.162 & 0.121 & 0.406 & 0.841 \\
\hline 23 & 0.194 & 0.077 & 0.154 & 0.090 & 0.902 \\
\hline 24 & 0.121 & 0.013 & -0.162 & 0.086 & 0.854 \\
\hline
\end{tabular}

blueprint are compared and analyzed from four aspects. It is concluded that the level of higher education under this model has been dramatically improved. The implementation effects and advantages of the system proposed in this paper are as follows.

5.4.1. At the School Level. In recent years, Japanese quality evaluation and guarantee policies have strengthened the connection between the evaluation system and the types and levels of university development. Standardize evaluation procedures and methods by formulating a strict evaluation system. All schools carry out quality construction by their announced plans and goals and maintain fairness and transparency in evaluation.

5.4.2. At the Investment Level. Japan has increased its investment in education in recent years and has increased education subsidies for state and private universities. Under such a policy, the higher education system can also be more complete, and the prospects are broader.

5.4.3. At the Output Level. Mainly due to the impact of the new crown epidemic, employment in Japan has gradually increased in recent years. The government analyzed that the lack of a workforce has led to high demand for corporate recruitment. In short, the employment rate in Japan and Japanese per capita scientific journal papers has been increasing this year. The number of patent applications and per capita is also gradually increasing, showing a healthy and sustainable state.

5.4.4. At the Overall Level. The Ministry of Education, Culture, Sports, Science, and Technology of Japan set out to formulate a new scholarship policy for high school and university students in 2014. Japanese annual high school fees of 400 billion yen will be changed from the Generalized System of Preferences to the focus of family income restrictions. In addition, to improve the fairness of higher education admission opportunities, Japan has implemented a three-pronged transformation to the uneven distribution of normal and secondary education resources. That is, government financial allocations are treated equally, allowing teachers and principals to implement regular mobility; according to different regions and economic development levels, different transfer payment ratios are determined to ensure that compulsory education treats children in rich and poor areas equally; the Japanese government directly bears the responsibility of mandatory education school teaching. The head fee of the staff eliminates the difference in the treatment of teachers in different schools. The provisions of these policies have enabled the teacher qualifications and hardware facilities of primary and secondary schools to reach the national standard even in remote and backward villages.

In summary, the results of the current higher education system in Japan that we have chosen are roughly similar to the healthy and sustainable system proposed above. Therefore, under this model, the country's higher education system can be improved. 


\section{Prediction of Policy Implementation Effect}

\subsection{Analysis of Higher Education Health Status Based on the ARMA Model}

6.1.1. ARMA Model Introduction. The ARMA model is a relatively mature model, suitable for short-term forecasting. The establishment of a model requires the time series to be random and stable. A large amount of data is needed, and a computer program needs to be written to identify the model. The ARMA model is the most mature time series forecasting model developed today, and it has unique advantages in capturing the linear information of the data. Support Vector Machine (SVM) is a machine learning method based on structural risk minimization. A large amount of literature uses the ARMA model to predict stock prices, the travel time of BRT vehicles, air-conditioning power consumption, etc. The overall process framework of the ARMA model is shown in Figure 4.

(1) AR Model. AR model is also called an autoregressive model. Its prediction method is to predict by a linear combination of past observations and current interference values. The mathematical formula of the autoregressive model is as follows:

$Y_{t}=H_{1} Y_{t-1}+H_{2} Y_{t-2}+\cdots+H_{p} Y_{t-p}+e_{t}$,

where $p$ is the order of the autoregressive model; $H_{i}(i=1,2, \ldots, p)$ is the undetermined coefficient of the model; $e_{t}$ is the error; $Y_{t}$ is a time series (18).

(2) MA Model. The MA model is also called the moving average model, and its prediction method is to predict the linear combination of the past interference value and the current interference value. The mathematical formula of the moving average model is as follows:

$$
Y_{t}=e_{t}-\theta_{2} e_{t-1}-\theta_{2} e_{t-2}-\cdots-\theta_{q} e_{t-q},
$$

where $q$ is the order of the model; $\theta_{i}(i=1,2, \ldots, q)$ is the undetermined coefficient of the model; $e_{t}$ is the error; $Y_{t}$ is the observed value (19).

(3) ARMA Model. The combination of the autoregressive model and the moving average model constitutes the autoregressive moving average model ARMA, used to describe the stationary random process. The mathematical formula is as follows:

$$
\begin{aligned}
Y_{t}= & H_{1} Y_{t-1}+H_{2} Y_{t-2}+\cdots+H_{p} Y_{t-p}+e_{t} \\
& -\theta_{1} e_{t-1}-\theta_{2} e_{t-2}-\cdots-\theta_{q} e_{t-q} .
\end{aligned}
$$

6.1.2. Model Establishment and Solving. This article firstly builds an ARMA-SVM combined forecasting model. It uses the ARMA model to predict the changes of each indicator in the next thirty years. Therefore, the linear change trend is included in the results of the ARMA model prediction, and then it uses the SVM model to predict its noncompliance. The linear part is finally weighted with the original data, and the optimal weight combination is selected to predict the

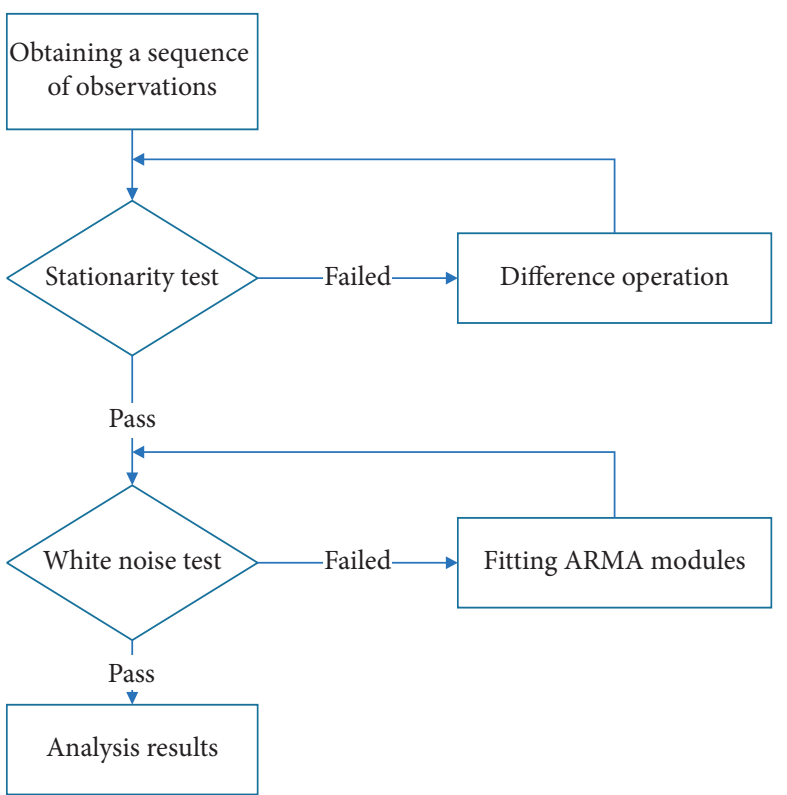

FIgURE 4: ARMA model flowchart.

various indicators of higher education. Finally, we use the evaluation model mentioned above to evaluate the predicted results after thirty years. It can be considered that the predicted evaluation results are the sustainable evaluation of national higher education.

The basic process of the optimal weighting method to determine the weight of the combined forecasting model: Let $t(t=1,2,3, \ldots, n)$ be the original time series, $n$ is the number of samples, the combined prediction model composed of these single models is as follows:

$$
\hat{y}_{i}=\sum_{i=1}^{m} w_{i} y_{\mathrm{it}}
$$

$\hat{y}_{i}$ represents the combined predicted value at time $t, w_{i}$ represents the weight of the $i$-th single prediction model, $y_{\text {it }}$ represents the predicted value of the $i$-th single model at time $t$.

$$
\sum_{i=1}^{m} w_{i}=1, w_{i} \geq 0, i=1,2,3, \ldots, m .
$$

Then set the prediction error of the $i$-th prediction model at time $t$ according to the above conditions $e_{i t}$

$$
\mathrm{e}_{\mathrm{it}}=y_{t}-y_{\mathrm{it}} \text {. }
$$

The formula $y_{t}$ represents the actual value at time $t, t=1,2,3$, ..., $n$, and the essence of the optimal weighting method is based on the principle of the formula. The principle of the smallest sum of squares of prediction errors determines the weighting coefficients of each single prediction model. Planning model at this time for

$$
\left\{\begin{array}{l}
\min M=\sum_{t=1}^{n} e_{i t}^{2} \\
\text { s.t. } \sum_{i=1}^{m} w_{i}=1, w \geq 0, i=1,2,3, \cdots, m
\end{array},\right.
$$


where $M$ is the objective function, the above formula is expressed as a matrix form: $W=\left[w_{1}, w_{2}, w_{3}, \ldots, w_{m}\right]^{T}$, Error information matrix. $E=\left[\begin{array}{cccc}e_{1}(1) & \cdots & \cdots & e_{1}(m) \\ \vdots & \ddots & \ddots & \vdots \\ \vdots & \therefore & \ddots & \vdots \\ e_{n}(1) & \cdots & \cdots & e_{n}(m)\end{array}\right]$ make $R=[1,1,1, \ldots, 1]$ is a one-dimensional vector with all 1 element, then the sum of squared errors of the combined prediction model $Q$ for

$$
\mathrm{Q}=\sum_{t=1}^{n} e^{2}=\sum_{t=1}^{n}\left(\sum_{i=1}^{m} w_{i} e_{\mathrm{it}}\right)^{2}=W^{T} \mathrm{EW} .
$$

Thus, the problem to be solved becomes the following optimization problem for solving constraints:

$$
\left\{\begin{array}{l}
\min Q=W^{T} \mathrm{EW} \\
\text { s.t } R^{T} W=1 \\
W \geq 0
\end{array}\right.
$$

\section{Lagrangian}

multiplier

factor, $Q=W^{T} \mathrm{EW}+\lambda\left(R^{T} W-1\right)$; to make $Q$ the smallest value, you need $W$. The first-order partial derivative is zero, that is,

$$
\frac{\partial Q}{\partial S}=2 \mathrm{EW}+\lambda R=0 .
$$

Get the optimal solution: $W=E^{-1} R / R^{T} E^{-1} R$. Calculate the sum of squared errors of the combined prediction model $Q$. The minimum value: $\min Q=1 / R^{T} E R$. At the same time, to ensure $E$ exist, which requires $m$ error vectors of each prediction model are linearly independent. The overall model framework is shown in Figure 5.

\subsubsection{Analysis of the Healthy Development Trend of Higher} Education. The use of the ARMA model requires that the time series be stable, and the original data needs to be tested for stationarity. This uses ADF inspection and KPSS inspection, as shown in Table 6 and Figure 6.

They are combined with the analysis of the time series forecast table. It can be seen from the time series forecast table that the health status of Japanese universities is gradually rising, showing an upward trend. Japanese university health expectation in 2046 is 8.21 , surpassing the Japanese university's health expectation of 7.9 , indicating that Japan has achieved the previously preset reasonable and expected vision of most universities in the world. Therefore, the implementation timetable interval is limited to 5 years, but the cycle is 30 years. And the period is adjusted to achieve the target expectations.

\subsection{Analysis of the Healthy Development Trend and Imple-} mentation Timetable of Higher Education. Based on the previous time series forecast table and the current development of the Japanese higher education system, targeted development policies and corresponding policy implementation timetables are proposed for the future development of Japanese higher education, including students (S1), teachers (T), schools (S2), communities, (C), and Country $(\mathrm{N})$; these five aspects are the future implementation direction of Japanese higher education policy. Regarding the period for policy implementation, we choose the 20 years from 2021 to 2041. The forecast timetable for higher education is shown in Figure 7.

6.2.1. Educational Implementation Policies for Students. Students from their home countries can complete their studies and receive higher education knowledge through government-funded scholarships and tuition subsidies when the family cannot afford expensive school expenses. This has resulted in a corresponding increase in the employment rate of students and the gross enrollment rate of fresh graduates. Because the policy implementation period is considerable, the scope of understanding will be wider, making the Japanese higher education model attractive to some international students. And it can increase the proportion of international students, increasing the number of talents that will eventually be cultivated.

\subsubsection{Policies on Teacher Education Implementation.} Since the increase in the gross enrollment rate of fresh graduates will make the teaching staff less than before the implementation of the policy, the proportion of full-time teachers during this period will also increase. Similar to the impact on students in the previous paragraph, because the Japanese higher education model is attractive to some foreign teachers, it will increase the proportion of foreign teachers and teachers with a background of studying abroad.

6.2.3. About the School's Education Implementation Policy. After implementing a strict evaluation system, the quality of institutions of higher learning will be improved, and the scale of enrollment will also increase accordingly. The final stage of policy implementation has covered the whole country. Therefore, during this accumulation period, the actual output of scientific research of higher education institutions will increase, and the ranking of solid subjects of higher education institutions may also rise.

6.2.4. Educational Implementation Policies in the Community. Due to the popularity of higher education and the acceptability of the masses, after implementing relevant policies, community publicity and the number of regular thought exchange meetings will increase. The penetration rate of community higher education will also increase due to the government's implementation of relevant policies for school faculty. After eliminating the difference in the treatment of teachers from different schools, the number of higher education institutions in the community will increase, and the higher education penetration rate will reach a very high level.

6.2.5. Regarding the National Education Implementation Policy. After the relevant policies are adjusted and changed, 


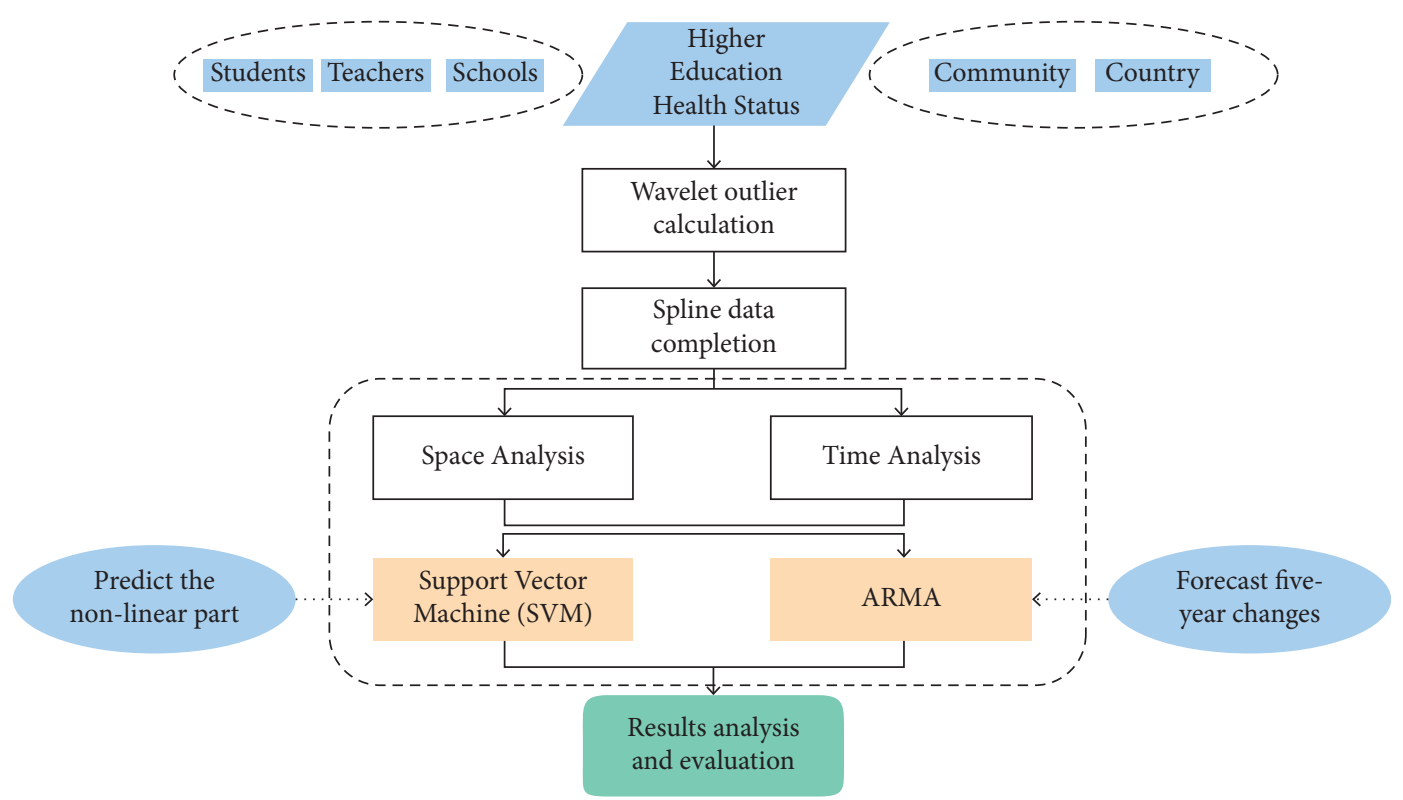

FIgURE 5: The ARMA-SVM-combined forecasting model.

Table 6: Time-series forecast table.

\begin{tabular}{ccccccccc}
\hline Model & & 2021 & 2026 & 2031 & 2036 & 2041 & 2046 & 2051 \\
\hline \multirow{3}{*}{ VINH } & FV & 5.16 & 5.91 & 6.34 & 7.42 & 8.09 & 8.21 & 9.18 \\
& LCL & 4.87 & 4.99 & 5.11 & 5.24 & 5.46 & 5.98 & 6.00 \\
& UCL & 7.13 & 8.45 & 9.01 & 10.01 & 10.43 & 11.03 & 11.99 \\
\hline
\end{tabular}

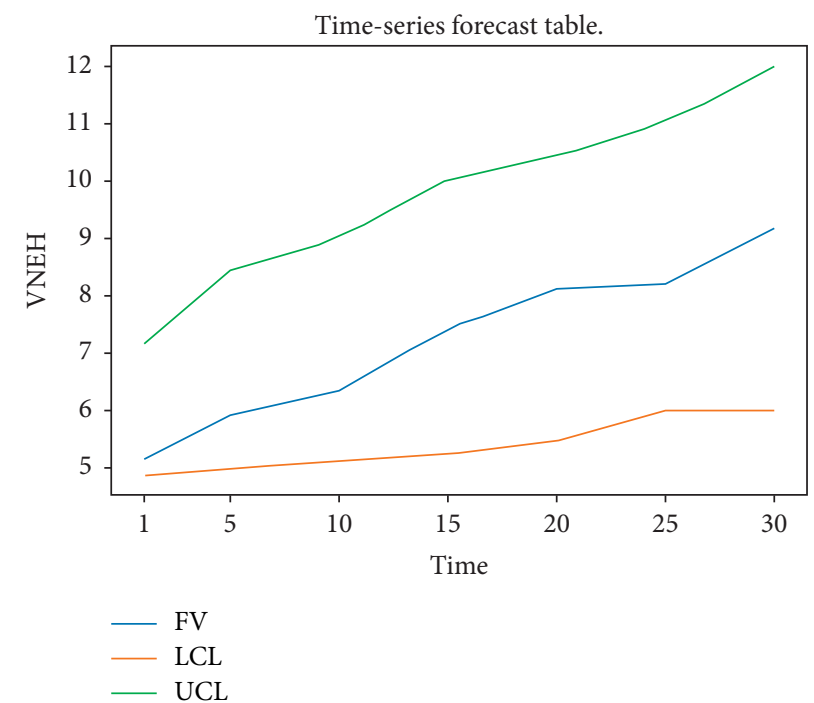

Figure 6: Time-series forecast table.

the government's expenditure on education funds will increase. At the same time, the number of funds allocated for education equity will be guaranteed. Then, the higher education system will be more complete. In addition to the implementation of domestic policies and the introduction of foreign talents, the number of national conferences held by countries in the final stage of the plan will increase significantly. With the exchanges of domestic and foreign experts and scholars, the output of high-level papers will also increase significantly. 


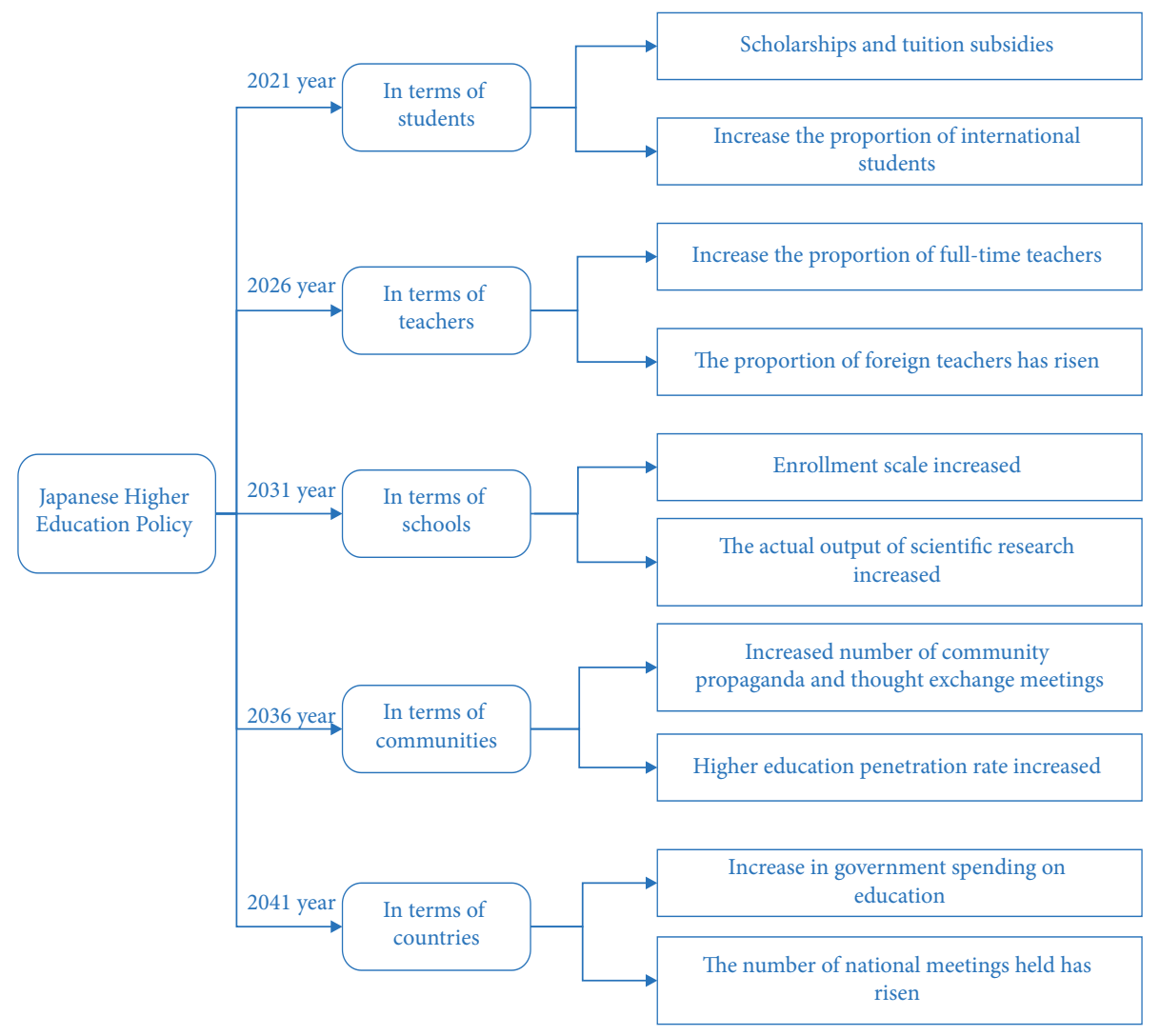

FIgURE 7: Schedule of Japanese higher education in the next 20 years.

\section{Conclusion}

According to the relevant theories of the evaluation model and the prediction model, this article establishes a comprehensive evaluation index system for the development level of higher education. And it uses a combination of subjective and objective evaluation methods, which calculate the scores of the development level of higher education in each country. After 20 years of comparing the level of healthy development in 18 countries, this paper found that European and American countries tend to have a higher level of development. However, the health level of higher education in Asian countries is relatively low. Finally, we further set Japan as a target country, proposing improvement policies and looking for core obstacles to the development of higher education. The article also proposes corresponding policy improvement plans and evaluates the effectiveness of the procedures we provide. The results show that the policies we propose enable Japan to obtain a higher education development score. In the next 20 years, the implementation of the Japanese higher education improvement policy was more pronounced, indicating that the empirical conclusions of this article are reasonable. In short, we believe that to achieve the requirements of higher education development, the international community should work together and actively cooperate. Countries should strengthen funding requirements in all aspects from students, teachers, schools, communities, and governments to provide the impetus for higher education and contribute to the future development of higher education. [39].

\section{Data Availability}

The data used to support the findings of this study are included within the article.

\section{Conflicts of Interest}

The authors declare that there are no conflicts of interest regarding the publication of this paper.

\section{Acknowledgments}

This work was supported by the Provincial Quality Engineering Project of Higher Education Institutions in Anhui Province, Provincial Education and Teaching Project, Research on the Establishment, Management and Evaluation Mechanism of College Art Clubs (no. 2020jyxm0003) and Research on A Probe into College Students' Identity Construction from a Speech Act Perspective (no. ACKYC20063).

\section{References}

[1] M. Withe-Korich and S. Bley, "Prospective educators as consumers of empirical research: an authentic assessment approach to make their competencies visible," Empirical Research in Vocational Education and Training, vol. 9, no. 1, pp. 1-26, 2017.

[2] C. Van Mol, K. Caarls, and M. Souto-Otero, "International student mobility and labour market outcomes: an investigation of the role of level of study, type of mobility, and 
international prestige hierarchies," Higher Education, vol. 82, no. 6, pp. 1-27, 2020.

[3] I. Reymert, J. Jungblut, and N. S. B. Borlaug, "Are evaluative cultures national or global? A cross-national study on evaluative cultures in academic recruitment processes in Europe," Higher Education, vol. 82, no. 5, pp. 1-21, 2020.

[4] P. Leahy and J. M. Salazar, "The moral dimension in Chilean higher education's expansion," Higher Education, vol. 74, no. 1, pp. 147-161, 2017.

[5] G. Yang, H. Fukuyama, and Y. Song, "Measuring the inefficiency of Chinese research universities based on a two-stage network DEA model," Journal of Informetrics, vol. 12, no. 1, pp. 10-30, 2018.

[6] D. Boud, P. Dawson, M. Meerman, S. Bennett, G. Joughin, and M. Elizabeth, "A multi-faceted formative assessment approach: better recognising the learning needs of students," Studies in Higher Education, vol. 43, no. 7, pp. 1107-1118, 2018.

[7] A. Raes, E. Vanderhoven, and T. Schellens, "Increasing anonymity in peer assessment by using classroom response Technology within face-to-face higher education," Studies in Higher Education, vol. 40, no. 1, pp. 565-576, 2015.

[8] S. S. Ahmad, K. Imrul, H. Kamrul et al., "Potential of ARMAANN, ARMA-SVM, D.T. And CatBoost for atmospheric PM2.5 forecasting in Bangladesh," Atmosphere, vol. 12, no. 1, p. $100,2021$.

[9] T. Green, "A methodological review of structural equation modeling in higher education research," Studies in Higher Education, vol. 41, no. 12, pp. 2125-2155, 2016.

[10] S. Tannock, "No grades in higher education now! Revisiting the place of graded assessment in the reimagination of the public university," Studies in Higher Education, vol. 42, no. 8, pp. 1345-1357, 2017.

[11] R. Wolf, D. Zahner, and R. Benjamin, "Methodological challenges in international comparative post-secondary assessment programs: lessons learned and the road ahead," Studies in Higher Education, vol. 40, no. 3, pp. 471-481, 2015.

[12] R. Harper, T. Bretag, C. Ellis et al., "Contract cheating: a survey of Australian university staff," Studies in Higher Education, vol. 44, no. 11, pp. 1857-1873, 2019.

[13] B. Margaret and A. Rola, "Can a rubric do more than be transparent? Invitation as a new metaphor for assessment criteria," Studies in Higher Education, vol. 46, no. 2, pp. 359-368, 2021.

[14] S. E. Hikichi, E. G. Salgado, and L. A. Baijo, "Forecasting number of ISO 14001 certifications in the Americas using ARMA models," Journal of Cleaner Production, vol. 147, pp. 242-253, 2017.

[15] B. Fanoodi, B. Malmir, and F. F. Jahantigh, "Reducing demand uncertainty in platelet supply chain through artificial neural networks and ARMA models," Computers in Biology and Medicine, vol. 113, p. 103415, 2019.

[16] B. Zhu, D. Han, P. Wang, Z. Wu, T. Zhang, and Y. M. Wei, "Forecasting carbon price using empirical mode decomposition and evolutionary least squares support vector regression," Applied Energy, vol. 191, no. APR.1, pp. 521-530, 2017.

[17] E. A. Hanushek and L. Woessmann, "Do better schools lead to more growth? Cognitive skills, economic outcomes, and causation," Journal of Economic Growth, vol. 17, no. 4, pp. 267-321, 2012.

[18] N. X. Zhang and S. Wang, "An evaluation and regional comparison of the holistic development of Chinese higher education," Educational Research, vol. 35, no. 5, pp. 28-36, 2014.
[19] W.-C. Chen, "How education enhances happiness: comparison of mediating factors in four east Asian countries," Social Indicators Research, vol. 106, no. 1, pp. 117-131, 2012.

[20] S. Marginson, "The worldwide trend to high participation higher education: dynamics of social stratification in inclusive systems," Higher Education, vol. 72, no. 4, pp. 413-434, 2016.

[21] J. Cuñado and F. P. de Gracia, "Does education affect happiness? evidence for Spain," Social Indicators Research, vol. 108, no. 1, pp. 185-196, 2012.

[22] E.-J. Lee and S. Y. Shin, "When do consumers buy online product reviews? effects of review quality, product type, and reviewer's photo," Computers in Human Behavior, vol. 31, pp. 356-366, 2014.

[23] Z.-P. Fan, Y.-J. Che, and Z.-Y. Chen, "Product sales forecasting using online reviews and historical sales data: a method combining the Bass model and sentiment analysis," Journal of Business Research, vol. 74, pp. 90-100, 2017.

[24] A. Abadie, A. Diamond, and J. Hainmueller, "Synthetic control methods for comparative case studies: estimating the effect of California's tobacco control program," Journal of the American Statistical Association, vol. 105, no. 490, pp. 493505, 2010.

[25] X. Xu, X. Wang, Y. Li, and M. Haghighi, "Business intelligence in online customer textual reviews: understanding consumer perceptions and influential factors," International Journal of Information Management, vol. 37, no. 6, pp. 673-683, 2017.

[26] Z.-P. Fan, G.-M. Li, and Y. Liu, "Processes and methods of information fusion for ranking products based on online reviews: an overview," Information Fusion, vol. 60, pp. 87-97, 2020.

[27] I. A. Yagci and S. Das, "Measuring design-level information quality in online reviews," Electronic Commerce Research and Applications, vol. 30, pp. 102-110, 2018.

[28] Y. Wang, X. Lu, and Y. Tan, "Impact of product attributes on customer satisfaction: an analysis of online reviews for washing machines," Electronic Commerce Research and Applications, vol. 29, pp. 1-11, 2018.

[29] Y.-H. Hu and K. Chen, "Predicting hotel review helpfulness: the impact of review visibility, and interaction between hotel stars and review ratings," International Journal of Information Management, vol. 36, no. 6, pp. 929-944, 2016.

[30] G. Aerts, T. Smits, and P. W. J. Verlegh, "How online consumer reviews are influenced by the language and valence of prior reviews: a construal level perspective," Computers in Human Behavior, vol. 75, pp. 855-864, 2017.

[31] S. Park and J. L. Nicolau, "Asymmetric effects of online consumer reviews," Annals of Tourism Research, vol. 50, pp. 67-83, 2015.

[32] S. Utz, P. Kerkhof, and J. Van Den Bos, "Consumers rule: how consumer reviews influence perceived trustworthiness of online stores," Electronic Commerce Research and Applications, vol. 11, no. 1, pp. 49-58, 2012.

[33] J. Chambua, Z. Niu, A. Yousif, and J. Mbelwa, "Tensor factorization method based on review text semantic similarity for rating prediction," Expert Systems with Applications, vol. 114, pp. 629-638, 2018.

[34] W. M. Wang, Z. Li, Z. G. Tian, J. W. Wang, and M. N. Chang, "Extracting and summarizing effective features and responses from online product descriptions and reviews: a Kansei text mining approach," Engineering Applications of Artificial Intelligence, vol. 73, pp. 149-162, 2018.

[35] J.-M. Zhu, Y. Chen, and S. Zhang, "Analysis of the impact of climate change on national vulnerability based on fuzzy 
comprehensive evaluation," Discrete Dynamics in Nature and Society, vol. 2020, Article ID 3527540, 10 pages, 2020.

[36] X.-B. Liu, Y.-J. Zhang, W.-K. Cui, Li-T. Wang, and J.-M. Zhu, "Development assessment of higher education system based on TOPSIS-entropy, hopfield neural network, and cobweb model," Complexity, vol. 2021, Article ID 5520030, 11 pages, 2021.

[37] R. Xie, R. Liu, X.-B. Liu, and J.-M. Zhu, "Evaluation of SMEs' credit decision based on support vector machine-logistics regression," Jurnal Matematika, vol. 2021, Article ID 5541436, 10 pages, 2021.

[38] F. Xu, Y.-A. Du, H. Chen, and J.-M. Zhu, "Prediction of fish migration caused by ocean warming based on SARMA model," Complexity, vol. 2021, Article ID 5553935, 9 pages, 2021.

[39] J.-M. Zhu, L. Wang, and J.-B. Liu, "Eradication of Ebola based on dynamic programming," Computational and Mathematical Methods in Medicine, vol. 2016, Article ID 1580917, 9 pages, 2016. 